\section{(A) OPEN ACCESS}

\title{
Effect of a nurse-coordinated prevention programme on cardiovascular risk after an acute coronary syndrome: main results of the RESPONSE randomised trial
}

\author{
Harald T Jorstad, ${ }^{1}$ Clemens von Birgelen, ${ }^{2}$ A Marco W Alings, ${ }^{3}$ Anho Liem, ${ }^{4}$ \\ Jan Melle van Dantzig, ${ }^{5}$ Wybren Jaarsma, ${ }^{6}$ Dirk J A Lok, ${ }^{7}$ Hans J A Kragten, ${ }^{8}$ \\ Keesjan de Vries, ${ }^{9}$ Paul A R de Milliano, ${ }^{10}$ Adrie J A M Withagen, ${ }^{11}$ \\ Wilma J M Scholte op Reimer, ${ }^{1}$ Jan G P Tijssen, ${ }^{1}$ Ron J G Peters ${ }^{1}$
}

For numbered affiliations see end of article.

\section{Correspondence to Harald Thune Jørstad, Department of Cardiology, Academic Medical Center- University of Amsterdam, Meibergdreef 9, P.O. Box 22660, Room F3-241, Amsterdam 1100 DD, The Netherlands; h.t.jorstad@amc.uva.nl}

Received 17 March 2013 Revised 30 May 2013 Accepted 31 May 2013 Published Online First 28 June 2013

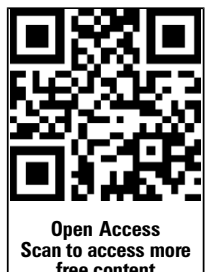

Scan to access mo free content

\footnotetext{
To cite: Jorstad HT, von Birgelen C, Alings AMW, et al. Heart 2013;99. 1421-1430.
}

\section{ABSTRACT \\ Objective To quantify the impact of a practical, hospital-based nurse-coordinated prevention programme on cardiovascular risk, integrated into the routine clinical care of patients discharged after an acute coronary syndrome, as compared with usual care only. Design RESPONSE (Randomised Evaluation of Secondary Prevention by Outpatient Nurse SpEcialists) was a randomised clinical trial. \\ Setting Multicentre trial in secondary and tertiary healthcare settings.}

Participants 754 patients admitted for acute coronary syndrome.

Intervention A nurse-coordinated prevention programme, consisting of four outpatient nurse clinic visits, focusing on healthy lifestyles, biometric risk factors and medication adherence, in addition to usual care. Main outcome measures The main outcome was 10-year cardiovascular mortality risk as estimated by Systematic Coronary Risk Evaluation at 12 months followup. Secondary outcomes included Framingham Coronary Risk Score at 12 months, in addition to changes in individual risk factors. Risk factor control was classified as 'poor' if 0 to 3 factors were on target, 'fair' if 4 to 6 factors were on target, and 'good' if 7 to 9 were on target.

Results The mean Systematic Coronary Risk Evaluation at 12 months was 4.4 per cent (SD 4.5) in the intervention group and 5.4 per cent (SD 6.2) in the control group $(p=0.021)$, representing a $17.4 \%$ relative risk reduction. At 12 months, risk factor control classified as 'good' was achieved in $35 \%$ of patients in the intervention group compared with $25 \%$ in the control group ( $p=0.003$ ). Attendance to the nurse-coordinated prevention programme was $92 \%$. In the intervention group, 86 rehospitalisations were observed against 132 in the control group (relative risk reduction $34.8 \%, p=0.023$ ).

Conclusions The nurse-coordinated hospital-based prevention programme in addition to usual care is a practical, yet effective method for reduction of cardiovascular risk in patients with coronary disease. Our data suggest that the counselling component of the programme may lead to a reduction in hospital readmissions.

Trial Registration trialregister.nl Identifier TC1290.

\section{INTRODUCTION}

Patients with established coronary artery disease (CAD) are at high risk of recurrent coronary events and mortality. Effective secondary prevention can reduce this risk, and comprehensive guidelines for the long-term management of patients with CAD have been issued by the American Heart Association/American College of Cardiology, ${ }^{1}$ and the European Society of Cardiology. ${ }^{2}$

At present, a considerable gap exists between these guidelines and their implementation in clinical practice. ${ }^{3}$ Nurse-coordinated prevention programmes may contribute to better achievement of preventive targets. Previous trials evaluating such initiatives have been performed in primary care, or have included complex multidisciplinary interventions. ${ }^{4-6}$ We designed the Randomised Evaluation of Secondary Prevention by Outpatient Nurse SpEcialists (RESPONSE) trial to quantify the impact of a practical, hospital-based nursecoordinated prevention programme integrated into the routine clinical care of patients who have sustained an acute coronary syndrome (ACS).

\section{METHODS}

Design

RESPONSE is a multicentre, randomised clinical trial that was conducted in 11 centres in The Netherlands. Detailed study methods have been published elsewhere and are summarised here. ${ }^{7}$ The protocol was approved by the institutional committees on human research of all recruiting hospitals.

\section{Trial participants}

Patients aged $18-80$ years were eligible if they had been diagnosed with an ACS (ST segment elevation myocardial infarction, non-ST segment elevation myocardial infarction or unstable angina pectoris), within 8 weeks prior to entry into the study. Patients were ineligible if they met any of the following exclusion criteria: visits to the nursecoordinated prevention programmes not feasible; not available for follow-up; surgery, percutaneous coronary intervention or other interventions expected within 8 weeks after inclusion; limited life 
expectancy ( $\leq 2$ years); previously enrolled in the nursecoordinated prevention programme; New York Heart Association class III or class IV heart failure.

\section{Recruitment and randomisation}

Written informed consent was obtained during or shortly after hospitalisation. Patients were subsequently randomised to either the nurse-coordinated prevention programme in addition to usual care (intervention group) or usual care alone (control group). The online randomisation protocol consisted of a pregenerated block-stratified randomisation protocol (http://www. responsestudie.nl). Study personnel entered patient's initials, date of birth and gender, and participating individuals were assigned a study identification number along with their allocation to either the intervention group or control group. ${ }^{7}$ All patients were informed about the subject of the study, that is, secondary prevention of coronary disease. However, in order to reduce a potential Hawthorne-effect, ${ }^{8}{ }^{9}$ we did not disclose the fact that patients were randomised to the nurse-coordinated prevention programme or usual care only. ${ }^{7}$ At the end of the trial, all information about the actual randomisation was provided to all patients. The institutional committees on human research explicitly approved this process of providing limited trial information to patients. The randomly assigned treatment of patients was not disclosed to treating cardiologists or general practitioners.

Usual care included outpatient clinic visits to treating cardiologists and other relevant specialists. This included referral to cardiovascular rehabilitation according to the national guidelines on cardiovascular rehabilitation. ${ }^{10}$ In short, cardiovascular rehabilitation typically consisted of a 12 week programme of evaluation of physical, psychological and social functioning, of providing education, physical exercise, and interventions to improve physical and social functioning and to improve cardiovascular risk factors and/or risk behaviour. ${ }^{10}$ Cardiologists were encouraged, in all patients, to adhere to current national and international guidelines for secondary prevention of cardiovascular disease.

\section{Nurse-coordinated prevention programme}

The programme included four outpatient clinic visits to a cardiovascular nurse during the first 6 months after inclusion: at weeks $2,7,12$ and 17 after baseline. The nurse-coordinated prevention programme followed a protocol based on national and international guidelines, focusing on (1) healthy lifestyles, (2) biometric risk factors and (3) medication adherence. ${ }^{1} 211$ The nine targets for the nurse-coordinated prevention programme are presented in box 1 .

During each visit, smoking status, dietary status, level of physical exercise, weight, waist circumference, blood pressure, total cholesterol, high-density lipoprotein (HDL) cholesterol, lowdensity lipoprotein (LDL) cholesterol, triglycerides, glucose and $\mathrm{HbA1c}$ were reviewed. Nurses provided general lifestyle advice, including dietary advice. Nurses provided specific educational material and individual counselling to achieve smoking cessation, adequate physical exercise and healthy weight/fat distribution. In collaboration with the responsible specialist, treatment of blood pressure and lipid levels was adjusted to achieve the target levels described in box 1 . This included titration of medication by the nurse or referral to other health professionals as needed. Patients with suspected, undiagnosed diabetes or diabetes with inadequate glucometabolic control were referred to their treating physician. Adherence to prescribed medication was encouraged at each visit, including antithrombotic therapy and a statin. If discontinued, reasons for discontinuation were documented, and if
Box 1 Targets for nurse-coordinated prevention programme

\section{Lifestyle and biometric targets \\ Smoking}

1. Not smoking

Anthropometry

2. Body mass index $<25 \mathrm{~kg} / \mathrm{m}^{2}$

3. Waist circumference: for women $\leq 80 \mathrm{~cm}$, for men $\leq 94 \mathrm{~cm}$

Blood pressure

4. Systolic blood pressure $<140 \mathrm{~mm} \mathrm{Hg}$

\section{Blood cholesterol}

5. $\mathrm{LDL}$ cholesterol concentration $\leq 2.5 \mathrm{mmol} / \mathrm{L}$

Physical activity

6. $\geq 30$ min of moderate intensity physical activity 5 times a week

Diet

7. Vegetable consumption $\geq 200$ grams daily

8. Fruit consumption $\geq 2$ pieces daily

9. Alcohol consumption: for women $\leq 2$ units per day, for men $\leq 3$ units per day

\section{Medication adherence}

Secondary cardiovascular preventive drug management

Preventive cardiovascular medications are prescribed as clinically indicated by responsible specialist or general practitioner, at doses used in usual care for all patients with coronary heart disease.

- Antiplatelet drugs

- B-blockers

- ACE inhibitors or angiotensin-II receptor blockers

- Lipid-lowering drugs (statins)

- Diuretics

possible the therapy was restarted. Between 6 months (end of the programme) and 12 months follow-up, there were no visits to the nurse-coordinated prevention programme.

Nurses contributing to the prevention programme were registered nurses with a 4-year bachelor's degree and experience in the care of cardiac patients ( $\mathrm{n}=15$ in 11 centers). They were selected by the local investigators and received at least one day of central training in cardiovascular risk management and 1 day of local individual training in using the study protocol in addition to investigators meetings. All nurses were given a 3-day course in motivational interviewing at the Department of Medical Psychology, Academic Medical Center in Amsterdam, the Netherlands. To assess their ability to deliver the intervention, individual nurses were observed on at least two separate occasions by study personnel. Video recordings were made of the nurses' consultations (with patients' permission) that were evaluated by a medical psychologist, who gave feedback to individual nurses.

\section{Follow-up and data collection}

We collected data at baseline, and at 6 months and 12 months follow-up. We recorded gender, educational status, work status, 
means, SD and 95\%-confidence intervals (95\% CI) were used to describe continuous variables; frequencies and percentages were used to describe categorical variables. Comparisons between groups were summarised as proportion (percentage) mean change (SD) and number, and independent samples t-tests, $\chi^{2}$ or Fisher's exact tests, Yates-Cochran and McNemar tests were applied. We used SPSS statistics V.18 for all statistical analyses.

With 754 patients in two groups, the study has more than $80 \%$ power to detect a difference of 1 point in SCORE function at 12 months between the two treatment groups, assuming a SD of 4.5 points.

\section{RESULTS}

Figure 1 presents the trial profile. Between June 2006 and July 20091666 patients were screened for study enrolment, whereof 1243 met eligibility criteria, and 754 provided consent and were randomised. In the intervention group, nine patients did not receive the intervention as randomised, and five patients did not complete follow-up (three died and two had early discontinuation of intervention). In the control group, 12 patients were excluded from the study and 18 patients did not complete follow-up (10 died, 1 lost to follow-up, 7 did not complete follow-up). Of 710 patients attending 12 months follow-up,
14 patients had incomplete outcome data and 696 patients $(92 \%)$ were included in the primary outcome analysis. The mean number of visits to the nurse-coordinated prevention programme was 3.8 , and $335 / 366(92 \%)$ of patients attended the maximum of all four visits.

Table 1 presents baseline patient characteristics. Patients had a mean age of 58 years and $80 \%$ were men. The majority of patients had no previous vascular history (73\%). The index event was ST elevation myocardial infarction in 49\%, a non-ST elevation myocardial infarction in 33\% and unstable angina pectoris in $18 \%$. Coronary revascularisation after the index event was performed in $79 \%$ of patients.

Table 2 presents the proportions of patients with risk factors on target. At 12 months, more patients in the intervention group versus the control group were on target for systolic blood pressure $(264(75 \%)$ vs $211(61 \%), \mathrm{p}<0.001)$, LDL cholesterol $(263(74 \%)$ vs $222(64 \%), p=0.007)$, physical activity (239 (66\%) vs $192(52 \%), \mathrm{p}<0.001)$, vegetable consumption (286 (80\%) vs $244(70 \%), \mathrm{p}=0.02)$ and fruit consumption (332 (93\%) vs $292(84 \%)$ p < 0.001). The prevalence of smoking significantly decreased in both groups, without any difference at 12 months between the two groups $(83(23 \%)$ vs $85(25 \%)$, $\mathrm{p}=0.72$ ). There was no difference between intervention and

Table 1 Patient characteristics by treatment group

\begin{tabular}{|c|c|c|c|c|}
\hline & \multicolumn{4}{|c|}{ No. (\%) of Patients* } \\
\hline & \multicolumn{2}{|c|}{$\begin{array}{l}\text { Nurse-coordinated prevention } \\
\text { programme } \\
(\mathrm{N}=366)\end{array}$} & \multicolumn{2}{|l|}{$\begin{array}{l}\text { Usual care } \\
\text { ( } \mathrm{N}=367)\end{array}$} \\
\hline Age (years), mean (SD) & 57.5 & $(9.9)$ & 57.8 & (10.4) \\
\hline Female, n (\%) & 73 & $(20 \%)$ & 74 & $(20 \%)$ \\
\hline \multicolumn{5}{|l|}{ Diagnostic category at index event } \\
\hline STEMI, n (\%) & 181 & $(50 \%)$ & 174 & $(48 \%)$ \\
\hline NSTEMI, n (\%) & 120 & $(33 \%)$ & 120 & $(33 \%)$ \\
\hline Unstable angina pectoris, $\mathrm{n}(\%)$ & 55 & $(17 \%)$ & 73 & $(19 \%)$ \\
\hline \multicolumn{5}{|l|}{ Therapeutic intervention for index event } \\
\hline No revascularisation, $\mathrm{n}(\%)$ & 71 & $(19 \%)$ & 79 & $(22 \%)$ \\
\hline Percutaneous coronary intervention, $\mathrm{n}(\%)$ & 282 & $(78 \%)$ & 271 & $(75 \%)$ \\
\hline Coronary artery bypass surgery, $\mathrm{n}(\%)$ & 20 & $(6 \%)$ & 22 & $(6 \%)$ \\
\hline \multicolumn{5}{|l|}{ Previous vascular disease (prior to index event) } \\
\hline Myocardial infarction, $\mathrm{n}(\%)$ & 60 & $(16 \%)$ & 65 & $(18 \%)$ \\
\hline Percutaneous coronary intervention, $\mathrm{n}(\%)$ & 46 & $(13 \%)$ & 55 & $(15 \%)$ \\
\hline Coronary artery bypass surgery, $\mathrm{n}(\%)$ & 19 & $(5 \%)$ & 19 & $(5 \%)$ \\
\hline Stroke, n (\%) & 14 & $(4 \%)$ & 10 & $(3 \%)$ \\
\hline Peripheral artery disease, $\mathrm{n}(\%)$ & 20 & $(6 \%)$ & 23 & $(6 \%)$ \\
\hline Congestive heart failure, $\mathrm{n}(\%)$ & 3 & $(1 \%)$ & 3 & $(1 \%)$ \\
\hline No known previous vascular disease, $\mathrm{n}(\%)$ & 269 & $(74 \%)$ & 266 & $(73 \%)$ \\
\hline \multicolumn{5}{|l|}{ History of cardiovascular risk factors, $\mathrm{n}(\%)$} \\
\hline Positive family history, $\mathrm{n}(\%)$ & 219 & $(60 \%)$ & 220 & $(60 \%)$ \\
\hline Diagnosed diabetes mellitus, n (\%) & 49 & $(13 \%)$ & 52 & $(14 \%)$ \\
\hline Dyslipidaemia, n (\%) & 254 & $(69 \%)$ & 263 & $(72 \%)$ \\
\hline Current smoking, $\mathrm{n}(\%) \dagger$ & 169 & $(46 \%)$ & 156 & $(43 \%)$ \\
\hline Ex-smoker, n (\%) & 134 & $(37 \%)$ & 143 & $(39 \%)$ \\
\hline Hypertension, n (\%) & 142 & $(39 \%)$ & 130 & $(36 \%)$ \\
\hline \multicolumn{5}{|l|}{ Educational } \\
\hline Fewer than 8 years, $\mathrm{n}(\%)$ & 51 & $(14 \%)$ & 47 & $(13 \%)$ \\
\hline College or university, n (\%) & 76 & $(21 \%)$ & 74 & $(20 \%)$ \\
\hline
\end{tabular}


Table 2 Number of risk factors on target by treatment group

\begin{tabular}{|c|c|c|c|c|c|c|c|c|c|c|c|c|c|c|c|c|}
\hline \multirow[b]{3}{*}{ Body mass index $\leq 25 \mathrm{~kg} / \mathrm{m}^{2}, \mathrm{n}(\%)$} & \multicolumn{4}{|c|}{ Baseline } & \multicolumn{4}{|c|}{6 months follow-up } & \multicolumn{4}{|c|}{12 months follow-up } & \multicolumn{2}{|l|}{ Within group } & \multicolumn{2}{|c|}{ Between group } \\
\hline & \multicolumn{2}{|c|}{$\begin{array}{l}\text { Nurse group } \\
(n=366)\end{array}$} & \multicolumn{2}{|c|}{$\begin{array}{l}\text { Usual care } \\
(n=367)\end{array}$} & \multicolumn{2}{|c|}{$\begin{array}{l}\text { Nurse group } \\
(n=358)\end{array}$} & \multicolumn{2}{|c|}{$\begin{array}{l}\text { Usual care } \\
(n=352)\end{array}$} & \multicolumn{2}{|c|}{$\begin{array}{l}\text { Nurse group } \\
(n=359)\end{array}$} & \multicolumn{2}{|c|}{$\begin{array}{l}\text { Usual care } \\
(n=348)\end{array}$} & \multirow{2}{*}{$\begin{array}{l}\begin{array}{l}\text { Nurse group } \\
\text { Baseline-12 } \\
\text { months } \\
\text { p Value }\end{array} \\
0.90\end{array}$} & \multirow{2}{*}{$\begin{array}{l}\begin{array}{l}\text { Usual care } \\
\text { Baseline-12 } \\
\text { months } \\
\text { p Value }\end{array} \\
0.28\end{array}$} & \multirow{2}{*}{$\begin{array}{l}6 \text { months } \\
\text { p Value }\end{array}$} & \multirow{2}{*}{$\begin{array}{l}12 \text { months } \\
\text { p Value } \\
0.09\end{array}$} \\
\hline & 84 & $(23 \%)$ & 105 & $(29 \%)$ & 75 & $(21 \%)$ & 88 & $(25 \%)$ & 77 & $(21 \%)$ & 94 & $(27 \%)$ & & & & \\
\hline Waist circumference men $\leq 94 \mathrm{~cm}$, women $\leq 80 \mathrm{~cm}, \mathrm{n}(\%)$ & 75 & $(21 \%)$ & 99 & $(27 \%)$ & 88 & $(25 \%)$ & 90 & $(26 \%)$ & 82 & $(23 \%)$ & 87 & $(25 \%)$ & 0.28 & 0.29 & 0.86 & 0.54 \\
\hline Systolic blood pressure $\leq 140 \mathrm{~mm} \mathrm{Hg}, \mathrm{n}(\%)$ & 248 & $(68 \%)$ & 267 & $(73 \%)$ & 256 & $(72 \%)$ & 228 & $(65 \%)$ & 264 & $(75 \%)$ & 211 & $(61 \%)$ & 0.02 & $<0.001$ & 0.05 & $<0.001$ \\
\hline LDL cholesterol $\leq 2.5 \mathrm{mmol} / \mathrm{L}, \mathrm{n}(\%)$ & 247 & $(68 \%)$ & 247 & $(68 \%)$ & 284 & $(80 \%)$ & 241 & $(69 \%)$ & 263 & $(74 \%)$ & 222 & $(64 \%)$ & 0.073 & 0.11 & 0.001 & 0.007 \\
\hline Current smoker*, n (\%) & 169 & $(46 \%)$ & 156 & $(43 \%)$ & 77 & $(22 \%)$ & 72 & $(21 \%)$ & 83 & $(23 \%)$ & 85 & $(25 \%)$ & $<0.001$ & $<0.001$ & 0.78 & 0.72 \\
\hline Physical activity $\geq 30$ min, $\geq 5$ times per week, $n(\%)$ & 185 & $(51 \%)$ & 185 & $(50 \%)$ & 257 & $(70 \%)$ & 202 & $(55 \%)$ & 239 & $(66 \%)$ & 192 & $(52 \%)$ & $<0.001$ & 0.60 & $<0.001$ & $<0.001$ \\
\hline $\begin{array}{l}\text { Alcohol consumption men } \leq 3 \text { units per day, } \\
\text { women } \leq 2 \text { units per day, } \mathrm{n}(\%)\end{array}$ & 347 & $(95 \%)$ & 340 & $(93 \%)$ & 346 & $(97 \%)$ & 336 & $(95 \%)$ & 346 & $(97 \%)$ & 331 & $(95 \%)$ & 0.02 & 0.004 & 0.27 & 0.35 \\
\hline Vegetables $\geq 200 \mathrm{~g}$ per day, $\mathrm{n}(\%)$ & 260 & $(71 \%)$ & 243 & $(66 \%)$ & 283 & $(80 \%)$ & 250 & $(71 \%)$ & 286 & $(80 \%)$ & 244 & $(70 \%)$ & $<0.001$ & 0.10 & 0.02 & 0.007 \\
\hline Fruit $\geq 2$ pieces per day, $n(\%)$ & 292 & $(80 \%)$ & 307 & $(84 \%)$ & 337 & $(95 \%)$ & 303 & $(86 \%)$ & 332 & $(93 \%)$ & 292 & $(84 \%)$ & $<0.001$ & 0.58 & $<0.001$ & $<0.001$ \\
\hline \multicolumn{17}{|l|}{ Other parameters } \\
\hline Triglyceride $\leq 2.0 \mathrm{mmol} / \mathrm{L}, \mathrm{n}(\%)$ & 291 & $(80 \%)$ & 291 & $(80 \%)$ & 287 & $(80 \%)$ & 280 & $(80 \%)$ & 277 & $(78 \%)$ & 279 & $(81 \%)$ & 0.052 & 0.80 & 0.93 & 0.41 \\
\hline $\mathrm{HDL}$ cholesterol $\geq 1.0 \mathrm{mmol} / \mathrm{L}, \mathrm{n}(\%)$ & 212 & $(58 \%)$ & 207 & $(57 \%)$ & 242 & $(68 \%)$ & 233 & $(67 \%)$ & 243 & $(69 \%)$ & 237 & $(69 \%)$ & $<0.001$ & $<0.001$ & 0.75 & 0.99 \\
\hline Diastolic blood pressure $\leq 90 \mathrm{mmHg}, \mathrm{n}(\%)$ & 313 & $(86 \%)$ & 319 & $(87 \%)$ & 310 & $(87 \%)$ & 291 & $(83 \%)$ & 297 & $(84 \%)$ & 276 & $(80 \%)$ & 0.73 & 0.005 & 0.14 & 0.14 \\
\hline Total cholesterol $\leq 4.5 \mathrm{mmol} / \mathrm{L}, \mathrm{n}(\%)$ & 257 & $(70 \%)$ & 255 & $(70 \%)$ & 280 & $(78 \%)$ & 247 & $(70 \%)$ & 254 & $(71 \%)$ & 251 & $(73 \%)$ & 0.93 & 0.67 & 0.02 & 0.74 \\
\hline
\end{tabular}

Data are $n(\%)$

${ }^{*}$ Number of patients currently smoking, data presented at baseline represents smoking status prior to index event. 
Table 3 Risk factor change at 6 months and 12 months by treatment group

\begin{tabular}{|c|c|c|c|c|c|c|c|c|c|c|c|c|c|c|}
\hline \multirow[b]{3}{*}{ Weight, kg (SD) } & \multicolumn{4}{|c|}{ Value at baseline } & \multicolumn{4}{|c|}{ Change at 6 months } & \multicolumn{4}{|c|}{ Change 12 months } & \multirow{3}{*}{$\begin{array}{l}6 \text { months } \\
\text { p Value } \\
0.62\end{array}$} & \multirow{3}{*}{$\begin{array}{l}12 \text { months } \\
\text { p Value } \\
0.38\end{array}$} \\
\hline & \multicolumn{2}{|c|}{$\begin{array}{l}\text { Nurse group } \\
(n=366)\end{array}$} & \multicolumn{2}{|c|}{$\begin{array}{l}\text { Usual care } \\
(n=367)\end{array}$} & \multicolumn{2}{|c|}{$\begin{array}{l}\text { Nurse group } \\
(\mathrm{n}=357)\end{array}$} & \multicolumn{2}{|c|}{$\begin{array}{l}\text { Usual care } \\
(n=352)\end{array}$} & \multicolumn{2}{|c|}{$\begin{array}{l}\text { Nurse group } \\
(\mathrm{n}=359)\end{array}$} & \multicolumn{2}{|c|}{$\begin{array}{l}\text { Usual care } \\
(n=348)\end{array}$} & & \\
\hline & 87.2 & $(15.7)$ & 84.2 & $(14.3)$ & 0.05 & $(7.3)$ & 0.3 & (7.8) & -0.5 & $(11.3)$ & 0.2 & $(10.6)$ & & \\
\hline Body mass index, $\mathrm{kg} / \mathrm{m}^{2}$ (SD) & 28.3 & (4.4) & 27.4 & $(4.0)$ & 0.03 & $(2.4)$ & 0.1 & $(2.5)$ & -0.2 & $(4.2)$ & 0.03 & (3.3) & 0.72 & 0.38 \\
\hline Waist circumference, cm (SD) & 100.4 & (13.6) & 98.6 & $(13.0)$ & -1.3 & $(13.2)$ & 0.2 & $(10.2)$ & -1.9 & (13.6) & 0.2 & $(14.3)$ & 0.1 & 0.048 \\
\hline Systolic blood pressure, mm Hg (SD) & 132.7 & (21.3) & 131.5 & $(19.8)$ & -0.8 & (18.5) & 2.7 & (18.9) & -0.1 & (17.1) & 4.2 & (18.9) & 0.014 & 0.002 \\
\hline Diastolic blood pressure, $\mathrm{mm} \mathrm{Hg}$ (SD) & 79.1 & $(11.5)$ & 78.6 & $(11.3)$ & 1.2 & $(11.4)$ & 2.6 & $(12.4)$ & 1.9 & (11.1) & 3.0 & $(11.4)$ & 0.01 & 0.20 \\
\hline Total cholesterol, mmol/L (SD) & 4.1 & $(1.0)$ & 4.1 & $(1.0)$ & -0.1 & $(1.1)$ & 0.03 & $(0.9)$ & -0.01 & $(1.2)$ & 0.02 & $(1.0)$ & 0.076 & 0.71 \\
\hline LDL cholesterol, mmol/L (SD) & 2.2 & $(0.9)$ & 2.3 & $(0.8)$ & -0.1 & $(1.0)$ & -0.05 & $(0.9)$ & -0.1 & $(1.0)$ & 0.03 & (0.8) & 0.21 & 0.16 \\
\hline HDL cholesterol, mmol/L (SD) & 1.1 & $(0.3)$ & 1.1 & $(0.4)$ & 0.1 & $(0.3)$ & 0.03 & $(0.5)$ & 0.1 & $(0.4)$ & 0.02 & $(0.5)$ & 0.22 & 0.16 \\
\hline Triglyceride, mmol/L (SD) & 1.6 & (1.4) & 1.5 & $(0.8)$ & -0.1 & $(1.1)$ & -0.003 & $(0.8)$ & -0.01 & $(0.9)$ & -0.03 & $(0.8)$ & 0.22 & 0.71 \\
\hline
\end{tabular}

control group in body mass index (BMI) and waist circumference at 12 months. In the intervention group, an increase was observed in the number of patients on target at 12-months follow-up as compared with baseline for systolic blood pressure (248 (68\%) to $264(75 \%), p=0.02)$, physical activity $(185(51 \%)$ to $139(66 \%), \mathrm{p}<0.001)$ and vegetable consumption $(260(71 \%)$ to $286(80 \%), \mathrm{p}<0.001)$. Conversely, in the control group, risk factor control deteriorated for systolic blood pressure (267 $(73 \%)$ to $211(61 \%), \mathrm{p}<0.001)$, and remained unchanged for physical activity $(185(50 \%)$ to $192(52 \%), \mathrm{p}=0.60)$ and vegetable consumption (243 (66\%) to $244(70 \%), \mathrm{p}=0.10)$.

Table 3 presents mean risk factor levels at baseline and changes at 6 months and 12 months. Weight, BMI and waist circumference decreased slightly in the intervention group while remaining unchanged in the control group in 12 months (weight -0.5 (SD 11.3) vs 0.2 (SD 10.6), $\mathrm{p}=0.38, \mathrm{BMI}-0.2$ (SD 4.2) vs 0.03 (SD 3.3), $\mathrm{p}=0.38$, waist circumference $-1.9 \mathrm{~cm}$ (SD 13.6) vs $0.2 \mathrm{~cm}$ (SD 14.3), $\mathrm{p}=0.048$ ). Systolic blood pressure remained unchanged in the intervention group, while an increase was observed in the control group $(-0.1 \mathrm{~mm} \mathrm{Hg}$ (SD 17.1) vs $4.2 \mathrm{~mm} \mathrm{Hg}$ (SD 18.9), $\mathrm{p}=0.002$ for difference in change).

Figure 2 presents the results of the primary outcome of the study. The SCORE cardiovascular 10-year mortality risk at baseline was 5.3 per cent (SD 6.5) in the intervention group and 5.2 per cent (SD 5.5) in the control group $(\mathrm{p}=0.74)$. At 6 months follow-up, SCORE was 4.4 per cent (SD 4.8) in the intervention group and 5.0 per cent (SD 5.5) in the control group $(p=0.12)$, corresponding with an absolute reduction of 0.96 per cent $(p<0.001)$ in the intervention group and an absolute reduction of 0.19 per cent $(p=0.47)$ in the control group. At 12 months, SCORE was 4.4 per cent (SD 4.5) in the intervention group and 5.4 per cent (SD 6.2) in the control group $(p=0.021)$, amounting to an absolute reduction of 0.93 per cent relative to baseline in the intervention group $(p<0.001)$ and an increase of 0.17 per cent $(p=0.38)$ in the control group. The difference in SCORE between the intervention and control group at 12 months represents a $17.4 \%$ reduction in estimated 10 -year cardiovascular mortality.

The results of the FCRS were consistent with those of SCORE. At baseline, FCRS was 8.5 per cent (SD 5.7) in the intervention group and 8.1 per cent (SD 5.5) in the control group $(\mathrm{p}=0.31)$. At 6 months, FCRS was 6.9 per cent (SD 5.0) in the intervention group and 7.4 per cent (SD 5.0) in the control group $(\mathrm{p}=0.17)$. At 12 months, FCRS was 7.0 per cent (SD 5.2) in the intervention group and 8.0 per cent (SD 5.7) in the control group $(p=0.017)$. This amounts to an absolute reduction of 1.5 per cent relative to baseline in the intervention group $(p<0.001)$, and a decrease of 0.05 per cent in the control group $(p=0.78)$. The difference in FCRS between the intervention group and control group at 12 months represents a $12.5 \%$ reduction in 10 -year incidence of coronary mortality and morbidity.

Figure 3 presents the classification of patients according to the number of risk factors on target. At 12 months, risk factor control was classified as 'good' in 128 (35\%) patients in the intervention group compared with 91 (25\%) in the control group $(\mathrm{p}=0.003)$.

Diabetes mellitus was diagnosed in 9 patients in the intervention group compared with 10 patients in the control group $(p=0.99)$. Based on measurements at follow-up visits, an additional 23 patients in the intervention group and 25 patients in the control group $(p=0.77)$ qualified for the diagnosis of diabetes mellitus. However, treating physicians did not establish a formal diagnosis of diabetes mellitus in any of these patients.

Table 4 presents the cumulative number of readmissions in 12 months. In total, there were 86 rehospitalisations in the

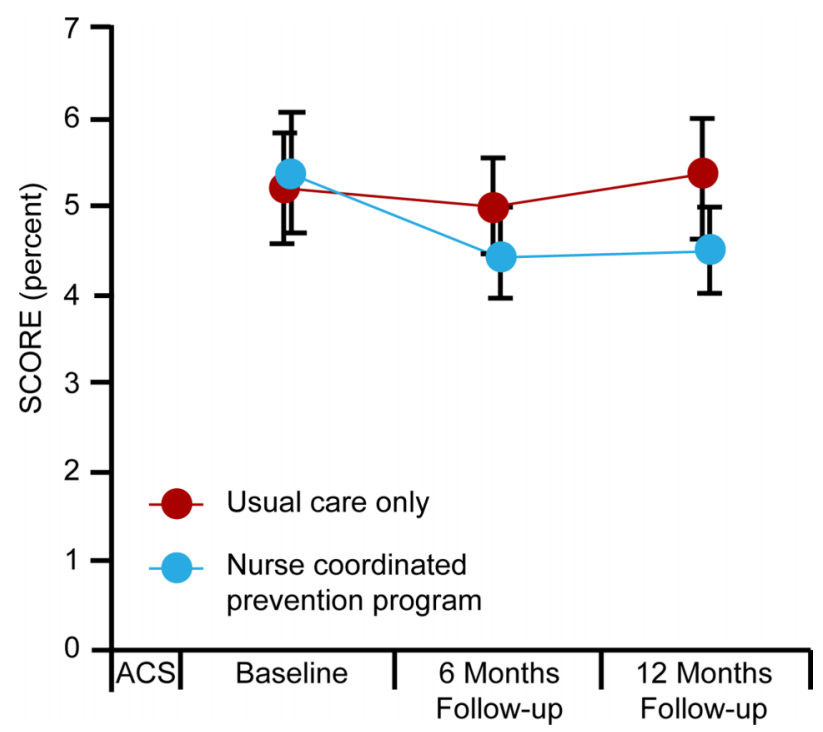

Figure 2 SCORE cardiovascular mortality estimation. SCORE at baseline, 6 months and 12 months. Error bars show 95\%-Cls. $\mathrm{ACS}=$ acute coronary syndrome. 


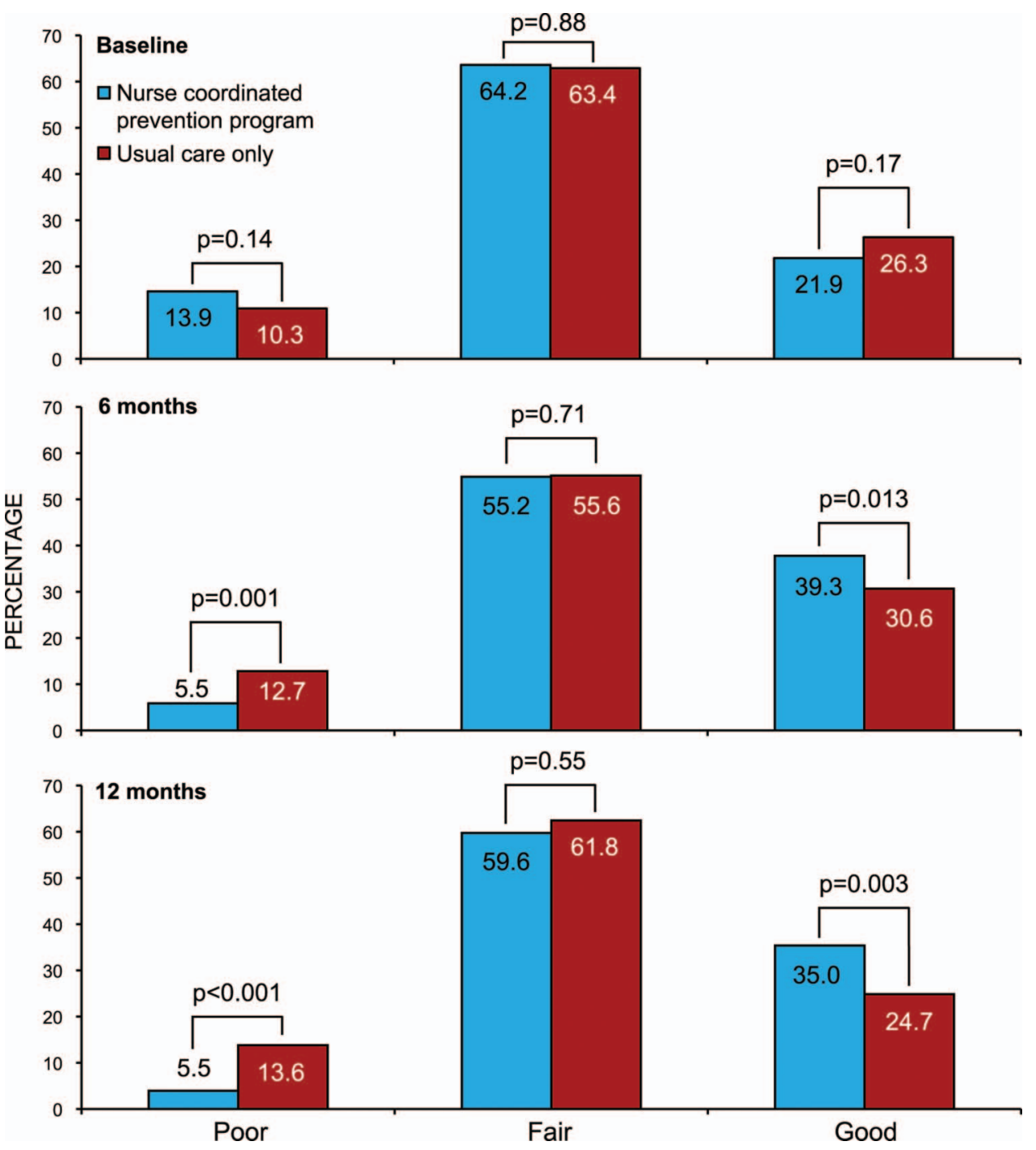

Figure 3 Classification of achievement of risk factor targets per patient (\%). Poor control is classified as 0-3 risk factors, fair control is classified as 4-6 risk factors and good control is classified as 7-9 risk factors on target. Risk factors are smoking, body-mass index $<25 \mathrm{~kg} / \mathrm{m} 2$, waist circumference for women $\leq 80 \mathrm{~cm}$, waist circumference for men $\leq 94 \mathrm{~cm}$, systolic blood pressure $<140 \mathrm{~mm} \mathrm{Hg}$, LDL cholesterol $\leq 2.5 \mathrm{mmol} / \mathrm{L}$, physical activity $\geq 30$ min $\geq 5$ times per week, vegetable consumption $\geq 200$ grams daily, fruit consumption $\geq 2$ pieces daily, alcohol consumption for women $\leq 2$ units per day, alcohol consumption for men $\leq 3$ units per day.

intervention group against 132 in the control group $(\mathrm{p}=0.023)$. This difference was driven by a $67 \%$ reduction in readmissions for non-ACS chest pain (12 admissions vs 36 admissions, $\mathrm{p}<0.001)$. Cardiology emergency room visits occurred less frequently in the intervention group ( 29 visits vs 51 visits, $\mathrm{p}=0.036$ ), while cardiology outpatient visits were slightly more common (822 visits vs 778 visits, $\mathrm{p}=0.20$ ). Readmissions for ACS and elective interventions were comparable in both groups.

Table 5 presents adherence to preventive cardiovascular medication. The use of antithrombotic agents and lipid lowering agents was high in both groups. The majority of patients used blood pressure lowering medication. In the intervention group diuretics $(76(21 \%)$ vs $53(15 \%), \mathrm{p}=0.04)$ and ACE inhibitors (201 (57\%) vs $160(46 \%), \mathrm{p}=0.005)$ were more frequently prescribed.

\section{DISCUSSION}

The main finding of our study is that a practical, hospital-based nurse-coordinated prevention programme on top of usual care leads to a reduction in cardiovascular risk. This was observed using two different risk functions (SCORE and the FCRS) and a classification of patients according to the number of risk factors that were on target, including self-reported parameters of lifestyle. Moreover, we observed a decrease of in the number of rehospitalisations in the first 12 months for non-ACS chest pain, and fewer visits to the cardiac emergency room in patients attending the nurse-coordinated prevention programme.

The significant improvements in lifestyle parameters that were observed in the intervention group are not reflected in the SCORE or Framingham risk functions. The overall impact of the intervention may therefore be underestimated. The on-target analysis offers an alternative quantification of benefit, as it includes parameters on lifestyle. Compared with usual care alone, the intervention led to a $37 \%$ increase in the proportion of patients that was classified as having 'good' control of risk factors. This risk reduction was achieved against a background of a high level of usual care, with risk factor levels more favourable than those reported in the literature and with excellent adherence to medication. ${ }^{3}$ Although our study design included a specific feature to prevent Hawthorne effects, we cannot 
Table 4 Hospital readmissions, cardiac emergency room visits and cardiology outpatient visits

\begin{tabular}{|c|c|c|c|c|c|c|}
\hline \multirow[b]{2}{*}{$\begin{array}{l}\text { Total number of } \\
\text { readmissions }\end{array}$} & \multirow{2}{*}{$\begin{array}{c}\begin{array}{l}\text { Total } \\
(\mathrm{n}=710)\end{array} \\
218\end{array}$} & \multicolumn{2}{|c|}{$\begin{array}{l}\text { Nurse } \\
\text { group } \\
(n=361)\end{array}$} & \multicolumn{2}{|c|}{$\begin{array}{l}\text { Usual care } \\
(\mathrm{n}=349)\end{array}$} & \multirow{2}{*}{$\begin{array}{l}\begin{array}{l}\mathbf{p} \\
\text { Value }\end{array} \\
0.023\end{array}$} \\
\hline & & 86 & $(39 \%)$ & 132 & $(61 \%)$ & \\
\hline Readmissions for ACS & 38 & 17 & $(45 \%)$ & 21 & $(55 \%)$ & 0.58 \\
\hline STEMI & 12 & 4 & $(33 \%)$ & 8 & $(67 \%)$ & 0.35 \\
\hline NSTEMI & 8 & 4 & $(50 \%)$ & 4 & $(50 \%)$ & 0.99 \\
\hline UAP & 18 & 9 & $(50 \%)$ & 9 & $(50 \%)$ & 0.98 \\
\hline $\begin{array}{l}\text { Other CVD } \\
\text { readmissions }\end{array}$ & 82 & 21 & $(26 \%)$ & 61 & $(74 \%)$ & $<0.001$ \\
\hline Chest pain no ACS & 48 & 12 & $(25 \%)$ & 36 & $(75 \%)$ & 0.001 \\
\hline Atrial fibrillation & 9 & 2 & $(22 \%)$ & 7 & $(78 \%)$ & 0.09 \\
\hline Congestive HF & 6 & 0 & $(0 \%)$ & 6 & $(100 \%)$ & 0.034 \\
\hline CVA & 3 & 1 & $(33 \%)$ & 2 & $(67 \%)$ & 0.57 \\
\hline Others & 16 & 6 & $(38 \%)$ & 10 & $(63 \%)$ & 0.40 \\
\hline Interventions & 29 & 12 & $(41 \%)$ & 17 & $(59 \%)$ & 0.41 \\
\hline CAG & 6 & 2 & $(33 \%)$ & 4 & $(67 \%)$ & 0.42 \\
\hline $\mathrm{PCl}$ & 21 & 9 & $(43 \%)$ & 12 & $(57 \%)$ & 0.54 \\
\hline CABG & 2 & 1 & $(50 \%)$ & 1 & $(50 \%)$ & 0.99 \\
\hline Elective interventions & 98 & 48 & $(49 \%)$ & 50 & $(51 \%)$ & 0.68 \\
\hline CAG & 61 & 32 & $(52 \%)$ & 29 & $(48 \%)$ & 0.67 \\
\hline $\mathrm{PCl}$ & 26 & 12 & $(46 \%)$ & 14 & $(54 \%)$ & 0.74 \\
\hline CABG & 11 & 4 & $(36 \%)$ & 7 & $(64 \%)$ & 0.37 \\
\hline $\begin{array}{l}\text { Cardiac emergency room } \\
\text { visits }\end{array}$ & 80 & 29 & $(36 \%)$ & 51 & $(64 \%)$ & 0.036 \\
\hline $\begin{array}{l}\text { Outpatient cardiology } \\
\text { visits }\end{array}$ & 1600 & 822 & $(51 \%)$ & 778 & $(49 \%)$ & 0.20 \\
\hline
\end{tabular}

Data are numbers of admissions, interventions or visits (\%) as applicable. ACS, acute coronary syndrome; CABG, coronary artery bypass surgery; CAG, coronary angiography; CVA, cerebrovascular accident; CVD, cardiovascular disease; $\mathrm{HF}$, heart failure; NSTEMI, non-ST segment elevation myocardial infarction; $\mathrm{PCl}$, percutaneous coronary interventions; STEMI, ST segment elevation myocardial infarction; UAP,

unstable angina pectoris.

exclude the possibility that the level of care in the control group has been positively influenced by participation in the trial. This could lead to an underestimation of the effects of the intervention. Compared with our control group, a sample of European patients had lower proportions of patients achieving risk factor targets, particularly in blood pressure control, total cholesterol, and use of lipid lowering therapy and blood pressure lowering agents. $^{3}$
The multinational EuroAction study showed results similar to our study. ${ }^{5}$ However, EuroAction included a complex, multidisciplinary intervention, while our study investigated the impact of a nursing intervention that is practical, feasible and integrated into routine clinical care. Consistent with our findings, Murchie and colleagues reported that nurse led prevention clinics in general practices in the UK improved medical and lifestyle components of secondary prevention. ${ }^{4}$ Our nurse-coordinated prevention programme took place in a hospital setting and, by comparison, we included younger patients (58 years vs 66 years) with a more recent coronary event. The optimal combination of intervention components, including content, mode of delivery, frequency and duration remains undetermined according to a recent meta-analysis. ${ }^{6}$ A more intensive intervention with more frequent visits could potentially further improve risk factor control, especially in complex patients, but this needs to be assessed in future studies. Our study adds to the existing evidence that a 6 months nurse-coordinated prevention programme, that can be easily implemented, leads to an overall decrease in cardiovascular risk that is sustained at 1 year after an ACS.

The observed difference in hospital readmissions for non-ACS chest pain and visits to the cardiac emergency ward was not anticipated. It may reflect the effectiveness of the counselling component of the nurse programme in preventing unnecessary hospital readmissions and emergency-room visits. However, this was a non-prespecified secondary outcome and this observation requires independent confirmation.

Ideally, the impact of a preventive intervention would be quantified at the level of individual mortality risk. For secondary prevention, individual predictors have been described. ${ }^{14}{ }^{15}$ However, these observations are based on short-term outcomes and, more importantly, no risk function is currently available that integrates all predictors into an overall estimation of cardiovascular mortality risk. For lack of a validated risk function in secondary prevention, we selected the SCORE function for 10 -year cardiovascular risk as the primary outcome in our secondary prevention trial. A recently published, comparable trial has similarly used a primary prevention risk score as the main outcome measure to quantify the effect of a secondary prevention programme. ${ }^{16}$ Although the absolute estimates of the SCORE function are inaccurate in secondary prevention, the difference in SCORE between the two groups provides an estimate of the relative overall impact of a risk factor intervention. Our analysis suggests a $17.4 \%$ relative risk reduction compared with usual care alone.

Table 5 Secondary cardiovascular preventive medication by treatment group

\begin{tabular}{|c|c|c|c|c|c|c|c|c|c|c|c|c|c|c|}
\hline \multirow[b]{3}{*}{ Any antithrombotic agent ${ }^{*}, \mathrm{n}(\%)$} & \multicolumn{4}{|c|}{ Baseline } & \multicolumn{4}{|c|}{6 months follow-up } & \multicolumn{4}{|c|}{12 months follow-up } & \multirow{3}{*}{$\begin{array}{l}6 \text { months } \\
\text { p Value } \\
0.99\end{array}$} & \multirow{3}{*}{$\begin{array}{l}12 \text { months } \\
\text { p Value } \\
0.99\end{array}$} \\
\hline & \multicolumn{2}{|c|}{$\begin{array}{l}\text { Nurse group } \\
(\mathrm{n}=366)\end{array}$} & \multicolumn{2}{|c|}{$\begin{array}{l}\text { Usual care } \\
(n=367)\end{array}$} & \multicolumn{2}{|c|}{$\begin{array}{l}\text { Nurse group } \\
(n=358)\end{array}$} & \multicolumn{2}{|c|}{$\begin{array}{l}\text { Usual care } \\
(n=352)\end{array}$} & \multicolumn{2}{|c|}{$\begin{array}{l}\text { Nurse group } \\
(n=355)\end{array}$} & \multicolumn{2}{|c|}{$\begin{array}{l}\text { Usual care } \\
(n=348)\end{array}$} & & \\
\hline & 363 & $(99 \%)$ & 363 & $(99 \%)$ & 354 & $(99 \%)$ & 354 & $(99 \%)$ & 348 & $(98 \%)$ & 342 & $(98 \%)$ & & \\
\hline Any lipid lowering agentt, $n(\%)$ & 350 & $(96 \%)$ & 352 & $(96 \%)$ & 345 & $(96 \%)$ & 337 & $(96 \%)$ & 331 & $(93 \%)$ & 328 & $(94 \%)$ & 0.70 & 0.64 \\
\hline$\beta$ Blockers, $\mathrm{n}(\%)$ & 328 & $(90 \%)$ & 326 & $(89 \%)$ & 296 & $(83 \%)$ & 285 & $(81 \%)$ & 270 & $(76 \%)$ & 272 & $(78 \%)$ & 0.56 & 0.53 \\
\hline Calcium channel blocker, $\mathrm{n}(\%)$ & 65 & $(18 \%)$ & 65 & $(18 \%)$ & 82 & $(23 \%)$ & 58 & $(17 \%)$ & 77 & $(22 \%)$ & 65 & $(19 \%)$ & 0.04 & 0.35 \\
\hline Diuretics, n (\%) & 52 & $(14 \%)$ & 52 & $(15 \%)$ & 74 & $(21 \%)$ & 53 & $(15 \%)$ & 76 & $(21 \%)$ & 53 & $(15 \%)$ & 0.06 & 0.04 \\
\hline ACE inhibitors, $\mathrm{n}(\%)$ & 200 & $(55 \%)$ & 175 & $(48 \%)$ & 209 & $(58 \%)$ & 162 & $(46 \%)$ & 201 & $(57 \%)$ & 160 & $(46 \%)$ & 0.001 & 0.005 \\
\hline Angiotensin II receptor blockers, $\mathrm{n}(\%)$ & 36 & $(10 \%)$ & 32 & $(9 \%)$ & 56 & $(16 \%)$ & 49 & $(14 \%)$ & 58 & $(16 \%)$ & 55 & $(16 \%)$ & 0.53 & 0.92 \\
\hline$\alpha$ Blockers, $n(\%)$ & 0 & $(0 \%)$ & 3 & $(1 \%)$ & 0 & $(0 \%)$ & 4 & $(1 \%)$ & 0 & $(0 \%)$ & 4 & $(1 \%)$ & 0.06 & 0.06 \\
\hline
\end{tabular}

Data are $\mathrm{n}(\%)$.

${ }^{*}$ Antithrombotic agents are aspirine, clopidogrel, dipyridamol or any oral anticoagulant

tLipid lowering agents are statins or non-statin lipid lowering agents. 
Although these results are encouraging, there is room for improvement. Weight loss was insufficient in both groups, in spite of an increase in self-reported adequate physical exercise and improved food choices. However, the intervention group had a mean decrease in waist circumference of $1.9 \mathrm{~cm}$, whereas the control group had an increase of $0.2 \mathrm{~cm}$, potentially reflecting the effects of lifestyle changes. The large number of smokers who quit in both groups could potentially have been a factor limiting weight loss. The slightly higher weight in the intervention group at follow-up may be explained by the higher weight at baseline and the slightly higher proportion of patients who quit smoking. Given the encouraging results in the pharmacological components of the programme, the most important opportunities for further improvement are found in lifestyle parameters. In particular, there is an unmet need for strategies for weight loss and smoking cessation.

Attendance to the nurse-coordinated prevention programme for the four visits in the first 6 months of the study was excellent. Patients were willing to visit the clinic and to complete the programme. Locally selected registered nurses with limited additional training were able to execute the programme and were comfortable with the protocol. Consequently, we believe the programme is feasible and practical and can be implemented into routine care. In addition, since the risk factors for atherosclerotic complications in other arterial territories are largely the same as in CAD, a similar approach may be considered for patients with cerebral and peripheral arterial disease.

\section{Limitations}

Some aspects of our trial warrant consideration. We excluded patients unable to attend the nurse clinics, and patients with a limited life expectancy. Potentially, this group of patients is older, sicker and less mobile than our study population. Possibly, patients with decreased mobility could benefit from other approaches, such as a telephonic nurse-coordinated prevention programme. However, this was not part of our investigation.

Our study population consisted of a slightly lower proportion of women as compared with other national and international surveys. In the European Action on Secondary and Primary Prevention by Intervention to Reduce Events (EUROASPIRE) III survey, performed in 22 countries in Europe (including the Netherlands), $27 \%$ of participants were women. ${ }^{3}$ In the Netherlands, 33\% of all hospital admissions (88 765) for ischaemic heart disease in 2011 were in women. ${ }^{17}$

We excluded patients aged $\geq 80$ years at the index event. Excluding these individuals lead to a slightly lower mean age (58 years) of our study population as compared with the mean age in other European cohorts of patients with ACS (eg, 62 years in EUROASPIRE III). ${ }^{3}$ The effects of a Nurse-coordinated prevention programme (NCPP) in patients $>80$ years of age cannot be derived from our findings.

Our data on physical activity were self-reported. While we collected data on the duration and intensity of the physical activity, we did not assess cardiopulmonary fitness or exercise capacity. Potentially, a relevant increase in exercise capacity could also have occurred in patients who exercised less than 150 min per week.

\section{CONCLUSION}

The RESPONSE trial demonstrates that a nurse-coordinated hospital-based prevention programme with up to four outpatient clinic visits in addition to usual care results in sustained lowering of cardiovascular risk in patients with coronary disease. The programme was well attended, practical and can be readily implemented into daily practice. In addition, our data suggest that the counselling component of the programme prevents unnecessary hospital readmissions.

\section{Author affiliations}

${ }^{1}$ Department of Cardiology, Academic Medical Center-University of Amsterdam, Amsterdam, Noord Holland, The Netherlands

${ }^{2}$ Department of Cardiology, Medisch Spectrum Twente and University of Twente, Enschede, The Netherlands

${ }^{3}$ Department of Cardiology, Amphia Hospital, Breda, The Netherlands ${ }^{4}$ Department of Cardiology, Admiraal de Ruyter Hospitals, Goes, The Netherlands

${ }^{5}$ Department of Cardiology, Catharina Hospital, Eindhoven, The Netherlands

${ }^{6}$ Department of Cardiology, Antonius Hospital Nieuwegein, Nieuwegein,

The Netherlands

${ }^{7}$ Department of Cardiology, Deventer Hospital, Deventer, The Netherlands

${ }^{8}$ Department of Cardiology, Atrium Medical Center, Heerlen, The Netherlands

${ }^{9}$ Department of Cardiology, Medical Center Leeuwarden South, Leeuwarden, The Netherlands

${ }^{10}$ Department of Cardiology, Tergooi Hospitals, Hilversum, The Netherlands

${ }^{11}$ Department of Cardiology, Reinier de Graaf Gasthuis, Delft, The Netherlands

Acknowledgements We would like to acknowledge the contribution of all the RESPONSE-nurses participating in the nurse-coordinated prevention programme: K Balhuizen, L Blom, J Doornenbal, A van Drimmelen, H Helmes, I Kreemer,

F Kuijper, R Lardinois, N Moerman, A Obbema, A Reijenga, I van Sleeuwen, L van Stetten, A Klein Twennaar, E Wolf, D van der Woude.

Contributors All authors participated in the design and conduct of the trial. Acquisition of data: HTJ, CvonB, AMWA, AL, JMvanD, WJ, DJAL, HJAK, KdeV, PARdeM, AJAMW, RJGP. Analysis and interpretation of data: HTJ, JGPT, RJGP. Drafting of the manuscript: HTJ, JGPT, RJGP. Critical revision of the manuscript for important intellectual content: HTJ, CvonB, AMWA, AL, JMvanD, WJ, DJAL, HJAK, KdeV, PARdeM, AJAMW, WJMSopR, JGPT, RJGP. Statistical analysis: HTJ, JGPT, RJGP. Obtained funding: RJGP. Administrative, technical or material support: HTJ, CvonB, AMWA, AL, JMvanD, JW, DJAL, HJAK, KdeV, PARdeM, AJAMW, JGPT, RJGP. Study supervision: HTJ.

Funding The study was sponsored by an unrestricted grant from AstraZeneca, The Netherlands. The sponsor had no role in the design, data collection, data analysis, data interpretation and writing of this report.

\section{Competing interests None.}

Ethics approval The institutional committees on human research of all recruiting hospitals.

Provenance and peer review Not commissioned; externally peer reviewed.

Data sharing statement Requests for analyses of de-identified data from this trial should be directed to: HTJ (h.t.jorstad@amc.uva.nl).

Open Access This is an Open Access article distributed in accordance with the Creative Commons Attribution Non Commercial (CC BY-NC 3.0) license, which permits others to distribute, remix, adapt, build upon this work non-commercially, and license their derivative works on different terms, provided the original work is properly cited and the use is non-commercial. See: http://creativecommons.org/ licenses/by-nc/3.0/

\section{REFERENCES}

1 Smith SC, Allen J, Blair SN, et al. AHA/ACC guidelines for secondary prevention for patients with coronary and other atherosclerotic vascular disease: 2006 update: endorsed by the National Heart, Lung, and Blood Institute. Circulation 2006;113:2363-72.

2 De Backer G, Ambrosioni E, Borch-Johnsen K, et al. European guidelines on cardiovascular disease prevention in clinical practice: third joint task force of European and other societies on cardiovascular disease prevention in clinical practice (constituted by representatives of eight societies and by invited experts). Eur J Cardiovasc Prev Rehabil 2003;10:S1-S10.

3 Kotseva K, Wood D, De Backer G, et al. EUROASPIRE III: a survey on the lifestyle, risk factors and use of cardioprotective drug therapies in coronary patients from 22 European countries. Eur J Cardiovasc Prev Rehabil 2009;16:121-37.

4 Murchie P, Campbell NC, Ritchie LD, et al. Secondary prevention clinics for coronary heart disease: four year follow up of a randomised controlled trial in primary care. BMJ 2003;326:84

5 Wood DA, Kotseva K, Connolly S, et al. Nurse-coordinated multidisciplinary, family-based cardiovascular disease prevention programme (EUROACTION) for patients with coronary heart disease and asymptomatic individuals at high risk of 
cardiovascular disease: a paired, cluster-randomised controlled trial. Lancet 2008;371:1999-2012.

6 Allen JK, Dennison CR. Randomized trials of nursing interventions for secondary prevention in patients with coronary artery disease and heart failure: systematic review. J Cardiovasc Nurs 2010;25:207-20.

7 Jørstad HT, Alings AMW, Liem AH, et al. RESPONSE study: Randomised Evaluation of Secondary Prevention by Outpatient Nurse SpEcialists: Study design, objectives and expected results. Neth Heart J 2009;17:322-8.

8 Braunholtz DA, Edwards SJ, Lilford RJ. Are randomized clinical trials good for us (in the short term)? Evidence for a "trial effect". J Clin Epidemiol 2001;54:217-24.

9 Mccarney R, Warner J, lliffe $S$, et al. The Hawthorne Effect: a randomised, controlled trial. BMC Med Res Methodol 2007;7:30.

10 Revalidatiecommissie Nederlandse Hartstichting/Nederlandse Vereniging voor Cardiologie. Richtlijn Hartrevalidatie. Den Haag: Nederlandse Hartstichting, 2004.

11 Burgers JS, Simoons ML, Hoes AW, et al. [Guideline 'Cardiovascular Risk Management']. Ned Tijdschr Geneeskd 2007;151:1068-74.
12 Conroy RM, Pyörälä K, Fitzgerald AP, et al. Estimation of ten-year risk of fatal cardiovascular disease in Europe: the SCORE project. Eur Heart J 2003:24:987-1003.

13 Wilson PW, D'Agostino RB, Levy D, et al. Prediction of coronary heart disease using risk factor categories. Circulation 1998;97:1837-47.

14 Bhatt DL, Eagle KA, Ohman EM, et al. Comparative determinants of 4-year cardiovascular event rates in stable outpatients at risk of or with atherothrombosis. JAMA 2010;304:1350-7.

15 D'Agostino RB, Russell MW, Huse DM, et al. Primary and subsequent coronary risk appraisal: new results from the Framingham study. Am Heart J 2000;139(2 Pt 1):272-81.

16 Vernooij JWP, Kaasjager HAH, Van Der Graaf Y, et al. Internet based vascular risk factor management for patients with clinically manifest vascular disease: randomised controlled trial. BMJ 2012:344:e3750.

17 Koopman C, Dis Iv, Bots M, et al. Hart- en vaatziekten in Nederland. In: Koopman C, van Dis I, Visseren FLJ, eds. Hart- en vaatziekten in Nederland 2012, cijfers over risicofactoren, ziekte en sterfte. Den Haag: Hartstichting, 2012:7-31. 